\title{
Factors Affecting Foreign Workers' Turnover Intentions
}

\author{
Myung-Hee JUNG ${ }^{1}$, Gil-Ju HWANG ${ }^{2}$
}

Received: October 14, 2019 Revised: October 23, 2019 Accepted: November 05, 2019

\begin{abstract}
Purpose: As the proportion of foreigners participating in the domestic labor market is gradually increasing, problems caused by social and cultural differences have also been expressed. As such, the purpose of this study was to analyze the effects of organizational justice and social support on psychological and cultural adaptation and its effect on turnover intention. Research design, data and methodology: The data was collected for foreign workers who visited the Foreign Workers Support Center operated by the Korea Human Resources Development Service. A total of 224 data were analyzed from March 1 to March 30, 2019 and was analyzed through frequency analysis for basic work environment of foreign workers, factor analysis for reliability and validity of variables, and overall structural model analysis. Results: Organizational fairness did not appear to affect psychological adaptation and significant cultural adaptation but social support had a significant effect. Psychological adjustment did not affect turnover intention, and cultural adaptation had a significant effect on turnover intention. Conclusions: Thus, in order to reduce the intention of turnover and adapt well to the working environment, it would be more efficient to find ways to raise the level of psychological adaptation by strengthening social support rather than organizational fairness.
\end{abstract}

Keywords : Organizational Justice, Social Support, Psychological Adaptation, Cultural Adaptation, Turnover Intention

JEL Classification Code : H75, I31, J15, R13

\section{Introduction}

As the size of the economy increases, the domestic labor market, where homogeneous workforce has become mainstream, is changing rapidly. The increase in women's labor force and human resources of the middle and old age group is an important change, but the rapid increase in the share of workers of different nationalities has also become an important shift in the dynamics of the workplace. According to the Monthly Immigration and Foreign Policy Report, the number of foreign workers entering Korea through the employment permit system more than doubled from 240,000 in 2006 to 53,693 by the end of 2018. This change in labor structure is transforming our society into a

1 First Author, Professor, Department of Social Welfare, Jungwon University, Republic of Korea. Email: jmhsubject@hanmail.net

2 Corresponding Author, Director General, Chungnam Branch Office, Human Resources Development Service of Korea, Republic of Korea. Email: lanke@naver.com

(c) Copyright: Korean Distribution Science Association (KODISA)

This is an Open Access article distributed under the terms of the Creative Commons Attribution Non-Commercial License (http://creativecommons.org/licenses/by-nc/4.0/) which permits unrestricted noncommercial use, distribution, and reproduction in any medium, provided the original work is properly cited. multi-cultural and multi-ethnical society (Kim, 2009). This phenomenon can be seen as a global trend rather than a singular change in Korea. For example, Japan, which has formed a homogeneous labor market for a long time similar to Korea, has experienced social issues due to the rapidly increasing multicultural labor force since the 1980s. This has been an important change in the workforce and the labor market.

Meanwhile, in order for Korean companies to be competitive in a fierce market environment, there has to be more support in addition to the government's continuous policy development for employment of foreign workers, as well as those in charge of the supply and demand of labor workers. This can amplify the sense of belonging or loyalty to the workplace in the company. It should also be accompanied by research from various perspectives to prevent high turnover rates and for workers to adapt well to the Korean working environment.

Accordingly, this study sets the intention of turnover rate as a dependent variable in order to grasp the sense of belonging or loyalty of foreign workers in domestic workplaces, and analyzes the relationship between organizational justice, social support, psychological 
adaptation and cultural adaptation. The purpose of this study is to enhance the adaptation of foreign workers and to suggest implications for their efficient management.

As a concrete method to achieve the purpose of this study, the present study first aims to grasp the current working environment, occupations and salaries of foreign workers. Second, the study attempted to verify whether organizational justice and social support significantly influenced psychological and cultural adaptation, respectively. Third, this study examined whether psychological and cultural adaptation had a significant effect on turnover intention. To this end, the structural relationship model of organizational fairness, social support, psychological adaptation, cultural adaptation, and turnover intention is set as a structural model. The results of this study was verified through the analysis of positive factors, confirmatory factors, and structural equations.

\section{Advanced Study Review}

\subsection{Foreign Workers}

In the domestic labor market, the low unemployment rate is still decent, but the labor market participation rate of women and young people is low, and the population structure is undergoing changes such as rapid aging of the population. The rapidly decreasing and low-skilled labor supply is aging. In particular, low-skilled jobs are often lowwage jobs due to the dual structure of the labor market, making it difficult for high-educated youth to flow freely (Ministry of Employment and Labor, 2019).

Migrant workers' migrant labor in Korea is being used as a response to labor demand, such as a lack of labor in lowwage jobs in manufacturing SMEs, and the inflow of foreign workers continues to increase, especially in low-skilled and temporary labor. Recently, small and medium-sized enterprises in Korea are unable to guarantee production capacity except for foreign workers. The large domestic inflows of foreign workers have a positive role in resolving the labor shortages of small and medium-sized manufacturing enterprises, securing stable productivity, and providing foreign workers with job opportunities. However, when foreign workers enter the country and are not able to adapt, resulting in them turning away, it can be a burden on the companies and the Korean society. If a foreign worker fails to adapt efficiently after being hired by a domestic company, it not only reduces teamwork among working members but also negatively affects job performance by reducing job satisfaction and organizational commitment.

If they fail to adapt successfully in the Korean society and leave the workplace or stay illegally, they can increase the costs of not only foreign workers themselves but also for companies and the society in general. At the end of 2018, the number of illegal residents of foreign workers was 355,126 , up $40 \%$ from 251,041 in 2017 , the highest level in the past five years. In fact, unfair management practices of foreign workers, the resulting departure from work, and issues leading to illegal stays are constantly being revealed. Illegal residence of foreign workers not only causes labor market disturbances, labor exploitation and human rights problems, but can also lead to social issues that incur significant social costs by increasing the difficulty of administrative management such as crackdown on illegal residence and forced departure. Additionally, foreign workers may be aware of workplace conflicts because of violence or verbal abuse by their Korean colleagues or supervisors.

In fact, interviews with foreign workers have found that many types of workplace conflicts, such as unilateral or positionally dominant Korean bosses or co-workers being unilaterally violent and verbal, or vice versa. Therefore, in order to effectively manage foreign workers and prevent their lack of adaptation, various studies on factors affecting the intention of turnover rates of foreign workers are needed.

\subsection{Organizational Fairness}

The issue of fairness in an organization can be said to be related to decision-making about the organization, such as promotion and transfer, performance appraisal, wage determination, transfer placement, and dismissal. In particular, the problem of fairness that foreign workers perceive and experience while working with Korean workers in Korea is an important issue for their psychological and cultural adaptation. Decisions regarding organizational members must have fairness and legitimacy recognized by all members of the organization. If there is an unfair decision that is not recognized by the members of the organization, the members of the organization who recognize the injustice will not only react negatively, such as frustration or job dissatisfaction, but will also lead to positive reactions such as absenteeism and turnover, leading to important problems that can impede organizational effectiveness.

Early research on organizational fairness began in the mid-1970s by organizational psychologists, with an emphasis on the procedural issue of distribution and an understanding at the organizational level. The reason for the rather late study of this procedural problem is that distribution fairness is primarily studied because the result of distribution to people is the most direct and final product, and the concept of distribution fairness has some meaning. In other words, considering the input-to-compensation ratio in the theory of fairness, it is possible to expand the interpretation that the procedure could be considered in the concept of broad input.

As research on the procedural problem of distribution has progressed, many studies have shown that even if the difference in distribution is evident, it becomes impossible for people to objectively compare the degree of input versus output between individuals who determines the difference. There was a loss of adequacy, and an effort was increasingly 
made to find a standard of fairness in whether the means or procedures used to achieve the outcome were applied fairly to oneself rather than a fair distribution of the outcome.

In recent years, more appropriate research has been carried out on variables and issues directly related to organizational functions, and in the late 1980s, it began to be dealt with under the theme of organizational justice. One of the major conflicts of fairness researchers had was in the form of the type of response that would have been formed if the workers did not receive the rewards that they deemed to be appropriate. Thus, two concepts of fairness were considered, one trying to explain what was treated fairly with the concept of distributive justice, and the other on how the extent of the procedural justice was determined. In this way, the focus of the attention had been shifted.

\subsection{Social Support}

The concept of social support is defined by various approaches by various scholars. This research on social support originated from ecological research aimed at examining the relationship between social environment and health. Later, Cobb (1976) first attempted the academic conceptualization of social support. Today, social support is social relations, social networks, social integration, social ties, social activities, adaptive resources, social support systems, social and psychological resources. Each researcher has a similar meaning as needed by the support network. Many researchers also view the existence, number, quantity, type, and frequency of social support as a measure of social support.

The general social support that the workers from migrant countries experienced is that it is a variable that has a positive influence on adaptation, in the form of help, and assistance provided by individual families, friends, neighbors, social groups and other service organizations. As a result, the various forms of social support provided by firms can help workers overcome many of the challenges they face in the field. Therefore, social support should be actively reviewed for the psychological and cultural adaptation of foreign workers and the intention to turnover rate.

\subsection{Psychological Adaptation}

Psychological adaptation is a concept that includes aspects of individual life as a whole. It is reported to have negative concepts such as depression, anxiety or stress, and positive concepts such as self-esteem, subjective well-being, and life satisfaction.

Existing studies have used both psychological adaptation as a dependent variable and verified both positive and negative aspects such as depression, anxiety, self-esteem, well-being, and life satisfaction factors.

Indeed, if we look at the meta-analysis of lifelong studies of psychiatric distress conducted by US clinical psychologists from 1970 to 1980 , people have different desires to reduce negative emotional states and increase positive ones. It was confirmed that the two systems function independently of each other.

Studies on psychological adaptation are mainly related to stress, loss experience, relative deprivation experiences, social anxiety and personality factors, and research on the changes in life after retirement in psychology and counseling has been conducted.

In this way, psychological adaptation can be understood as life satisfaction, and happiness along with stress or selfesteem, depression or anxiety, and the more stress that is experienced, the more inadequate aspects such as anxiety, depression, alienation, and identity confusion will exist.

Most studies on depression, anxiety, or life satisfaction with psychological adjustment mechanisms mainly focus on demographic and social, economic, and social factors. Verification of deprivation psychological adaptation is very meaningful.

\subsection{Cultural Adaptation}

Cultural adaptation is a change in the original cultural patterns of one or both groups as a result of continuous and direct contact within people of different cultures. Cultural contact occurs when people from different cultures meet. The interest in these adaptation problems in the context of cultural contact with these individuals define the concept of cultural adaptation. It is said that it is a process of change that results in mutual influence when the mutual contact between people of different cultural origins appears continuously. In addition, cultural adaptation can be divided into the group and individual aspects, and the collective dimension is a process that can take place between exchanges and interactions between two or more cultures. It is a process of cultural and psychological change that members of the cultural group face in contact with each other.

In other words, cultural adaptation may mean that the culture of the home country and the new culture are changed together by mutual influence, and not a new change that results in one culture.

Today, the concept of cultural adaptation included both social and psychological behavioral changes in individuals and groups, and John Powell first reported it in 1880 at the American Society of Anthropology, meaning "Psychological Change through Imitation of Other Cultures." The degree of cultural adaptation can be assessed as a measure of human development based on social nature through various interchangeable transformation processes.

Interest in various types of adaptation has increased since the 1970s, and the meeting of culturally diverse groups has an impact on each other's social structures, institutions, politics, and value systems, and the nature and extent of these changes depends on the conditions under which contact occurs. The results of cultural contact were divided into the individual level and group level results, and various 
forms were analyzed, as well as the change in cognition, attitude, and behavior at the individual level.

\subsection{Intention of Turnover Rates}

Worker turnover has important consequences for both workers and employers. Workers must give up the vested interest they have enjoyed in their careers, along with the benefits gained by turning a job, and the employer pays additional costs such as for new recruitment, training and adaptation. When a worker decides to turn a job, it will not be judged instantaneously. Moving a job should be made with careful considerations in many situations. The move before you make this choice is your intention to turn away. It can be inferred that not all of these intentions will be transferred, but in many cases they will choose to turn.

Turnover intention refers to the behavior or attitude of members of an organization to leave the organization and is a representative indicator of organizational effectiveness. The intention to move is defined as the degree to which an employee intends to give up being a member of the organization and leave his current job. In other words, turnover intention refers to the attitude or tendency of the individual to turn away. In addition, turnover intention is a state of psychological reaction of an individual in which a worker tries to leave the organization in a specific situation.

As such, the intention to turnover is interpreted as the willingness of the members to break the current relationship with the organization, and is evaluated as an effective substitute for the actual turnover behavior.

Various factors affect the turnover of employees, but it is known that factors related to work or work are more important in predicting turnover than individual characteristics. Existing studies also point out that not only job characteristics, but also various factors such as wage levels and relationships with co-workers are factors that influence employee turnover in the workplace.

\section{Study Method}

\subsection{Research Models and Hypotheses}

In order to achieve the purpose of this study based on previous studies, the research model as shown in [Figure 1] was set up and the hypothesis of $\mathrm{H} 1 \sim \mathrm{H} 6$ was derived based on this.

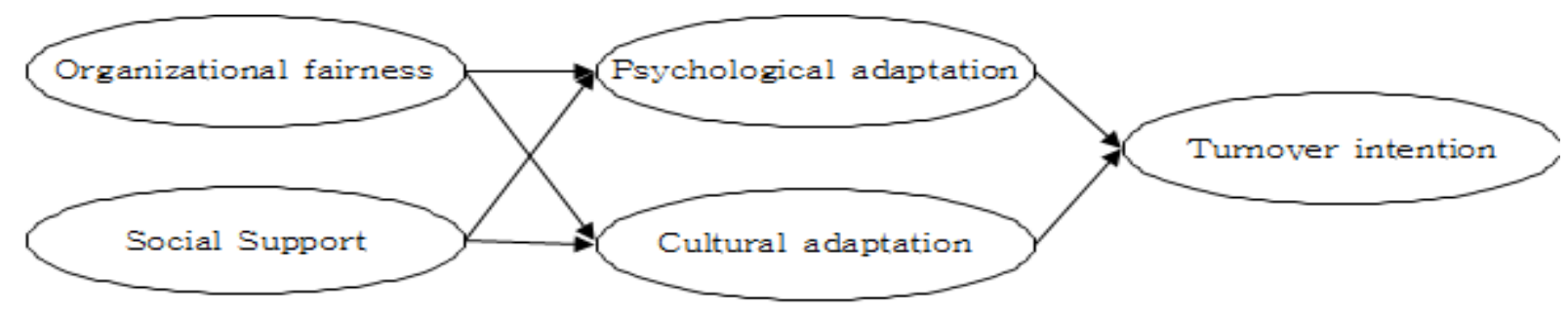

Figure 1: Research Model

H1. Organizational fairness will have a positive effect on psychological adaptation.

H2. Organizational fairness will have a positive effect on cultural adaptation.

H3. Social support will have a positive effect on psychological adaptation.

H4. Social support will have a positive effect on cultural adaptation.

H5. Psychological adaptation will have a positive effect on turnover intentions.

H6. Cultural adaptation will have a positive effect on turnover intentions.

\subsection{Data Collection and Analysis Method}

The sample for this study was for foreign workers who entered Korea through the employment permit system, and the data was collected for foreign workers who visited the Foreign Workers Support Center operated by the Korea Human Resources Development Service. A total of 224 data were analyzed from March 1, 2019 to March 30, except for poorly responded data. The data analysis verified the research hypothesis through frequency analysis for basic work environment analysis of foreign workers, factor analysis for reliability and validity of variables, and overall structural model analysis.

\subsection{Set Study Variables and Measurement Tools}

Each variable used in the research model was defined as operational based on previous studies as shown in $\langle$ Table 1$\rangle$, and the measurement tool was designed in consideration of the purpose of this study and the characteristics of foreign workers in Korea. 
Table 1: Measure of variable

\begin{tabular}{|c|c|c|c|c|}
\hline Division & $\begin{array}{c}\text { Variable } \\
\text { name }\end{array}$ & Operational definition & Questions & References \\
\hline $\begin{array}{l}\text { Independent } \\
\text { variable }\end{array}$ & $\begin{array}{l}\text { Organizational } \\
\text { fairness }\end{array}$ & $\begin{array}{l}\text { The degree of recognition that the set of rewards } \\
\text { (duty, compensation, promotion) given to foreign } \\
\text { workers and the criteria or processes used to } \\
\text { obtain them are fair. }\end{array}$ & 3 & $\begin{array}{l}\text { Bies \& Moag, 1986; Hyun-ho Seok et al., } \\
\text { 2003; Conlon et al., } 2005\end{array}$ \\
\hline Parameter & $\begin{array}{l}\text { Psychological } \\
\text { adaptation }\end{array}$ & $\begin{array}{l}\text { The degree of psychological adaptation of foreign } \\
\text { workers to new events and people in Korea }\end{array}$ & 3 & $\begin{array}{l}\text { Cheol-Kyun Jeong, 2007; Lee So-Hee } \\
\text { and Choi Un-Sun, 2008; }\end{array}$ \\
\hline $\begin{array}{l}\text { Dependent } \\
\text { variable }\end{array}$ & $\begin{array}{l}\text { Intention to } \\
\text { turn }\end{array}$ & $\begin{array}{c}\text { The degree of adaptation experienced by foreign } \\
\text { workers to Korea's new cultural environment } \\
\text { Attitudes or tendencies to voluntarily leave your } \\
\text { current company }\end{array}$ & 3 & $\begin{array}{l}\text { Choi Yun-ho, 2012; Kim Sang-wook and } \\
\text { Yoo Hong-jun, 2002; Firth et al., 2001; } \\
\text { Kim, Sun-Hee, 2005; Kim, Hyung-Seop, } \\
\text { 2005; Eom, Ki-Wook and In-A Park, 2007; } \\
\text { No, Ha-na, } 2007\end{array}$ \\
\hline
\end{tabular}

\section{Analysis Result}

\subsection{General Characteristics of Samples}

As shown in $\langle$ Table 2>, the nationality of Vietnam was $14.3 \%$, followed by Nepal $11.2 \%$ and Thailand $10.7 \%$. The gender of males was $74.6 \%$, which was higher than that of females $25.4 \%$, and the age group was the highest with $44.2 \%$ in their $30 \mathrm{~s}$, followed by $41.1 \%$ in their $20 \mathrm{~s}$. The marital status was similar to $48.7 \%$ of those that were married and $51.3 \%$ of those that were singles. Religion was followed by Buddhism 39.7\%, Non-religion $20.5 \%$ and Islam $17.0 \%$. The length of stay in Korea was $34.4 \%$ less than 3 years -5 years, $29.0 \%$ less than 1 year-3 years, $21.0 \%$ less than 5 years-10 years, $27.2 \%$ less than 3 years-5 years, and $20.5 \%$ less than 1 year. The average monthly salary was $47.3 \%$ less than KRW 1 million-2 million, and $46.4 \%$ was less than KRW 2 million-3 million, with $67.4 \%$ being workers in the manufacturing sector. In Korea, there was a rate of $40.2 \%$ in the Chungcheong region, $24.6 \%$ in the Gyeonggi region, and $12.1 \%$ in the region.

\subsection{Verification of Reliability and Validity of Measuring Tools}

Table 2: Demographic Characteristics of the Interviewees

\begin{tabular}{|c|c|c|c|}
\hline \multirow{3}{*}{ Nationality } & Section & Number of persons (persons) & Ratio (\%) \\
\cline { 2 - 4 } & China (Korean) & 21 & 9.4 \\
\cline { 2 - 4 } & Chinese (Han) & 4 & 1.8 \\
\hline
\end{tabular}

Exploratory Factor Analysis was conducted to understand how each factor is classified. Since there is no correlation between the factors due to the characteristics of the social science field, factors were extracted by the maximum likelihood method, and the factors were rotated by the oblimin method and analyzed as shown in <Table 3$\rangle$. The KMO measure was .813, and the Bartlett spherical test proved that the model was suitable with a significant probability of less than .05 .

As a result of reliability analysis, the credibility of organizational fairness (Cronbach's Alpha) was .874, and the intention to turnover was .756 , cultural adaptation was .821 , psychological adaptation was .829, and social support was .837. It was confirmed to be.

As a result of confirmatory factor analysis to verify the validity of the measurement model, the fitness of the measurement model for organizational fairness, social support, psychological adaptation, cultural adaptation and turnover intention is $\chi^{2}=141.522$ ( $\left.\mathrm{p}<.001\right)$, TLI It was confirmed that the level was satisfactory, with $=0.955$, CFI $=0.966$, and RMSEA $=0.059$. As shown in $\langle$ Table 4$\rangle$, the effects of latent variables on the observed variables were all significant at the significance level of .001. 


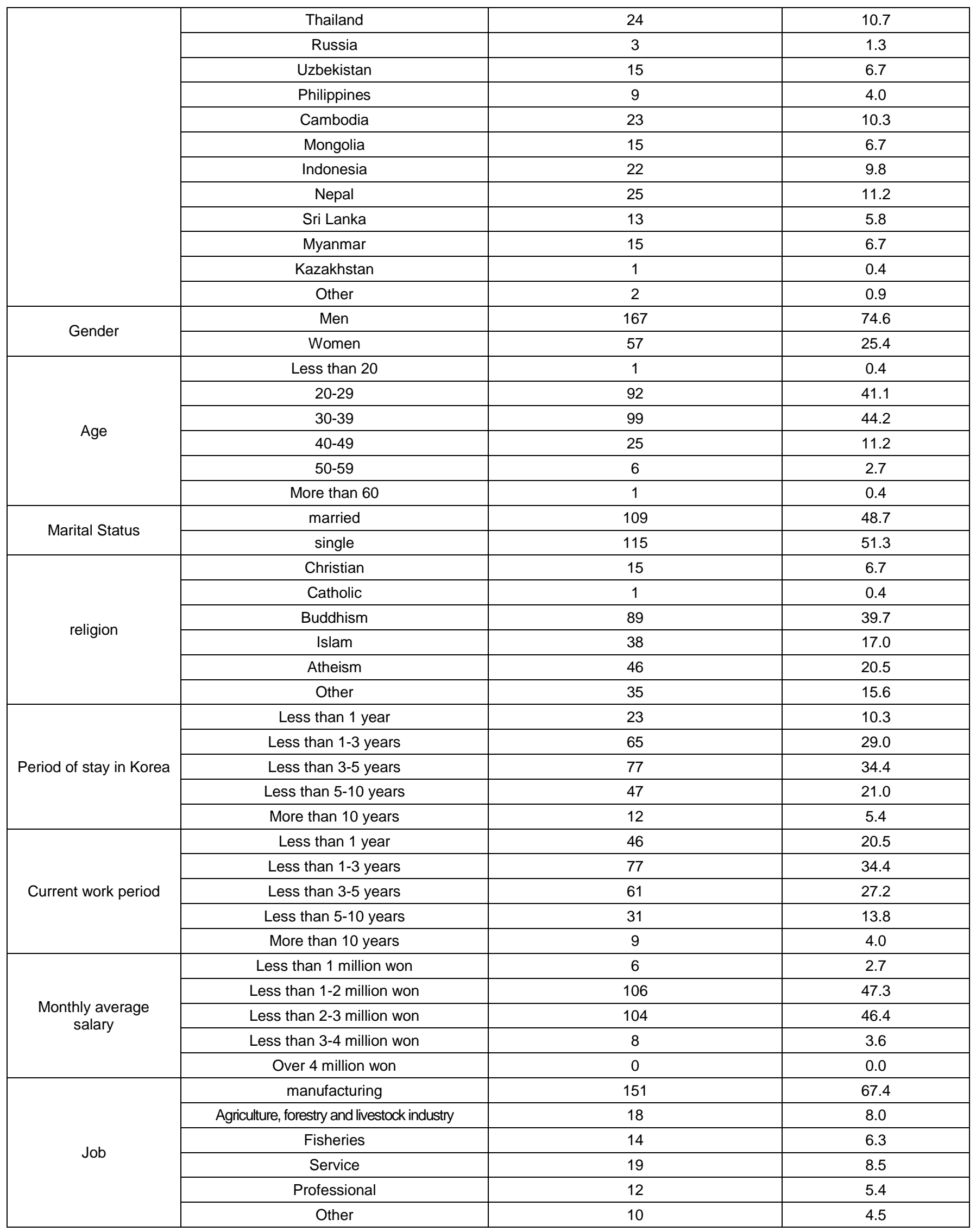


Myung-Hee JUNG, Gil-Ju HWANG / International Journal of Industrial Disribution \& Business Vol 10 No 11 (2019) 25-34

\begin{tabular}{|c|c|c|c|}
\hline \multirow{4}{*}{ Residency in Korea } & Seoul & 27 & 12.1 \\
\cline { 2 - 4 } & Gyeong-gi Area & 55 & 24.6 \\
\cline { 2 - 4 } & Gangwon Area & 9 & 4.0 \\
\cline { 2 - 4 } & Chungcheong Area & 90 & 40.2 \\
\cline { 2 - 4 } & Kyungsang Area & 26 & 11.6 \\
\cline { 2 - 4 } & Jeolla Area & 13 & 5.8 \\
\cline { 2 - 4 } & Jeju & 4 & 1.8 \\
\hline
\end{tabular}

Table 3: Exploratory Factor Analysis

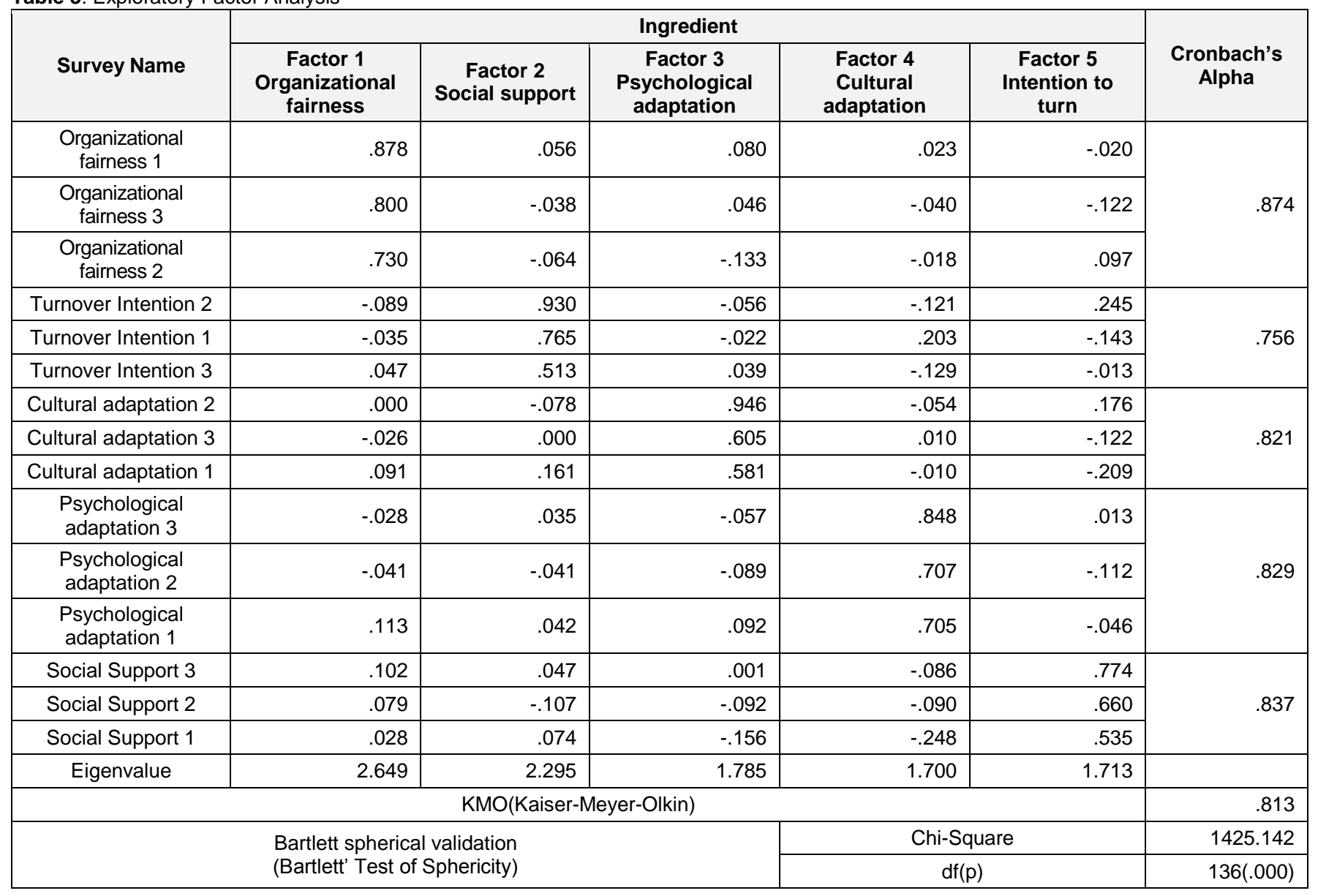

Table 4: Confirmatory Factor Analysis

\begin{tabular}{|c|c|c|c|c|c|c|}
\hline Division & $\begin{array}{c}\text { Non- } \\
\text { standardization } \\
\text { coefficient }\end{array}$ & S.E. & C.R. & $\begin{array}{l}\text { Standardization } \\
\text { coefficient }\end{array}$ & AVE & Reliability \\
\hline $\begin{array}{l}\text { Organizational Fairness } \rightarrow \\
\text { Organizational Fairness } 1\end{array}$ & 1 & & & 0.821 & \multirow{3}{*}{0.56271044} & \multirow{3}{*}{0.79320195} \\
\hline $\begin{array}{l}\text { Organizational Fairness } \rightarrow \\
\text { Organizational Fairness } 3\end{array}$ & 1.185 & 0.085 & $13.897^{\star * *}$ & 0.891 & & \\
\hline $\begin{array}{l}\text { Organizational Fairness } \rightarrow \overrightarrow{ } \\
\text { Organizational Fairness } 2\end{array}$ & 0.986 & 0.085 & $11.626^{\star * *}$ & 0.731 & & \\
\hline Social Support $\rightarrow$ Social Support 3 & 1 & & & 0.858 & \multirow{3}{*}{0.64189295} & \multirow{3}{*}{0.84276246} \\
\hline Social Support $\rightarrow$ Social Support 2 & 1.048 & 0.067 & $15.725^{\star * *}$ & 0.886 & & \\
\hline Social Support $\rightarrow$ Social Support 1 & 0.741 & 0.067 & $11.007^{\star \star \star}$ & 0.773 & & \\
\hline
\end{tabular}




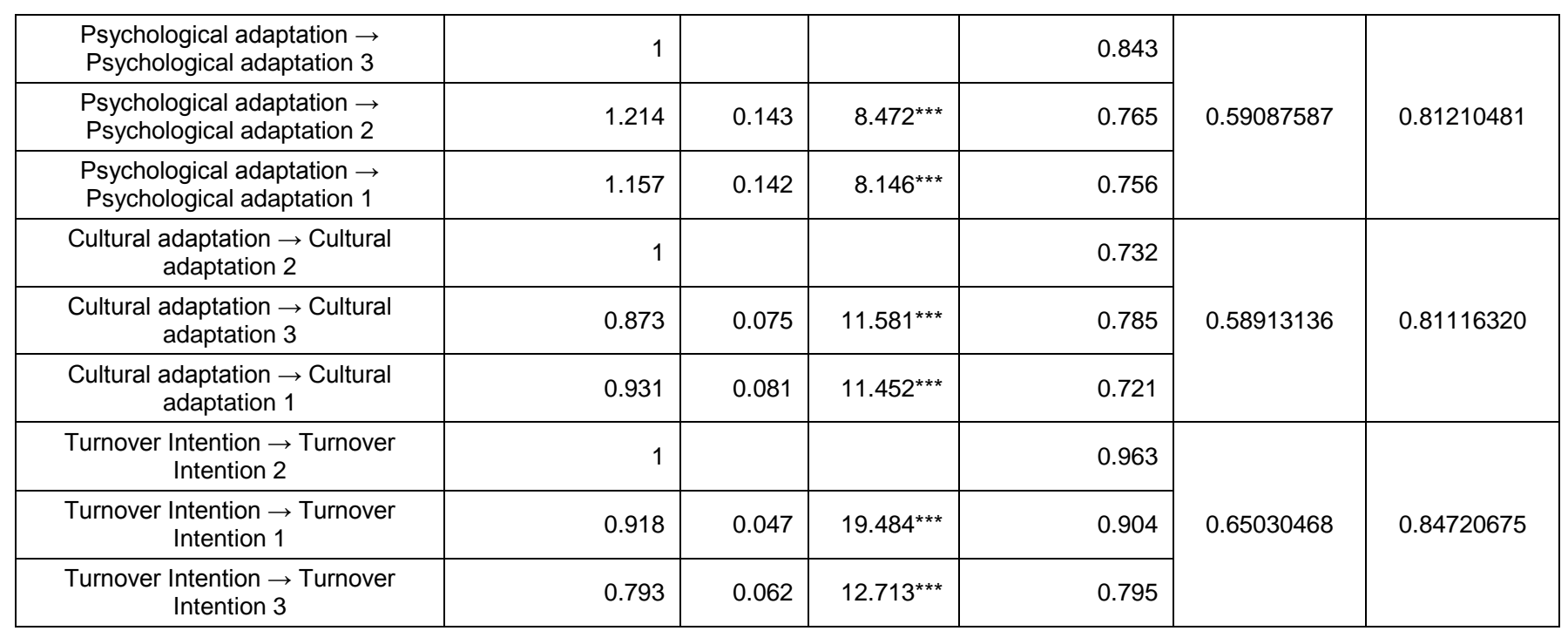

${ }^{* * *} \mathrm{p}<.001$

\subsection{Hypothesis Verification}

The structural model was analyzed as shown in <Figure $2>$ in order to examine the influence relations among the variables affecting the intention of turnover of foreign workers.

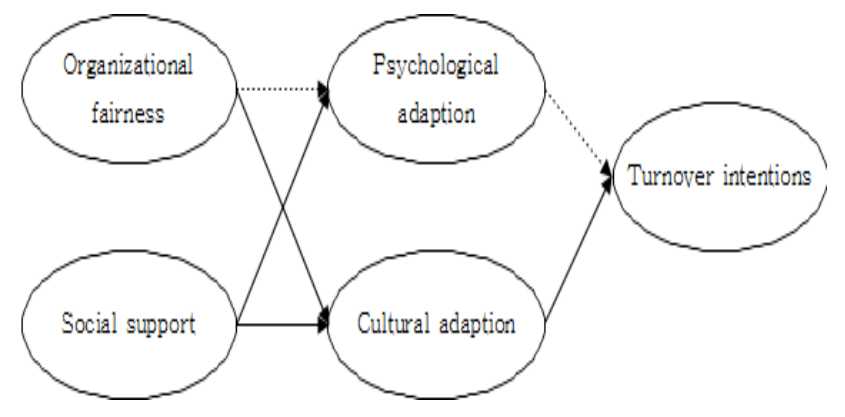

Figure 2: Result of structural model analysis
The goodness-of-fit of the structural model was found to be satisfactory with $\chi 2=153.092(\mathrm{p}<.001)$, TLI $=0.951$, $\mathrm{CFI}=0.961$, RMSEA $=0.062$ as a result of the structural model analysis, H1. Organizational fairness has not been shown to affect psychological adaptation, H2. Cultural adaptation was found to have a significant effect $(\beta=0.480$, $\mathrm{p}<.001)$. In other words, the higher the organizational fairness, the higher the cultural adaptation, H3. Social support was found to have a significant effect on psychological adaptation $(\beta=0.716, p<.001), \mathrm{H} 4$. It also showed a significant effect on cultural adaptation $(\beta=0.669$, $\mathrm{p}<.001$ ). In other words, the higher the social support, the higher the psychological and cultural adaptation, H5. Psychological adjustment did not appear to affect turnover intentions, H6. Cultural adaptation was found to have a significant effect on turnover intention $(\beta=0.295, \mathrm{p}<.001)$. In other words, the higher the cultural adjustment, the lower the intention for turnover.

Table 5: Path analysis result of structural model

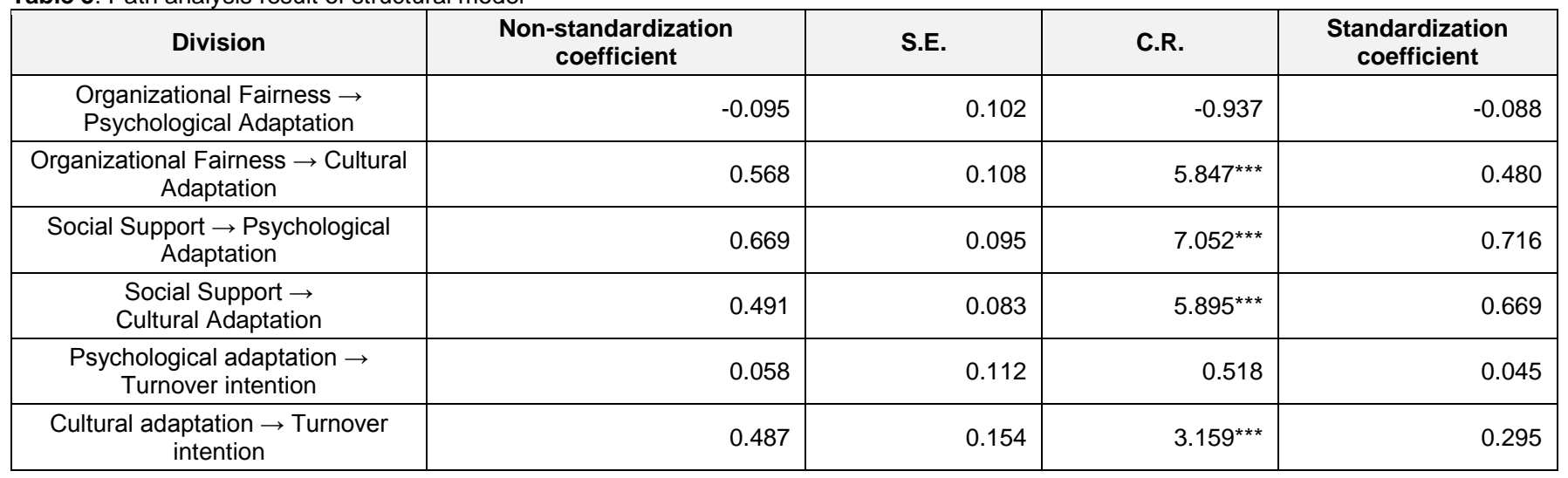




\section{Conclusions}

The purpose of this study was to identify the effect of organizational fairness, social support, psychological adaptation, and cultural adaptation on turnover intention in analyzing the factors that affected the turnover intention of foreign workers. Organizational Fairness, Social Support, Psychological Adaptation, and Cultural Adaptation are the main factors that migrant workers adapt to the private life and working environment, as shown in the previous studies. The main purpose was to identify what influenced those various factors.

In this study, hypotheses were set up for the purpose of research and conclusions were drawn through the research design.

First, we verified whether organizational fairness affected psychological and cultural adaptation. It was shown that cultural adaptation had a positive effect but did not seem to affect psychological adaptation. In short, the higher the organizational fairness, the higher the cultural adaptation was seen to be.

Second, we confirmed whether social support affected psychological and cultural adaptation, and both psychological and cultural adaptation showed positive effects. Thus, as social support increases, so did psychological and cultural adaptation.

Third, psychological and cultural adaptation were found to both affect turnover intention. However, psychological adaptation was found to have a positive effect but did not appear to affect cultural adaptation. In summary, the higher the psychological adjustment, the lower the turnover intention.

Finally, organizational justice and social support had a positive effect on cultural adaptation, and as cultural adaptation increased, the intention to turnover decreased. Increasing cultural adaptation through organizational fairness and social support lowered the intention to turnover, which can be analyzed as a factor to adapt and work longer in the workplace.

In discussing the results of the research, it was shown that foreign workers are adapting to Korean society by exchanging personal experiences, characteristics, working conditions, and adaptation. Therefore, a cultural approach will be needed in the future to help them be healthy psychologically.

First, it is necessary to proceed with cultural programs to help life adaptation. Foreign workers mainly work in industrial areas and live nearby. Therefore, they recognize that they are also important members of the community and develop as well as implement various programs to help them adapt to their daily lives, including language training, understanding of the Korean culture, and leisure and hobbies with local residents.

Second, in the era of internationalization and liberalization, we need to recognize the intrinsic meaning and value of other cultures and to change our perception of uniformity and homogeneity. We must now work together to eliminate prejudice against other cultures and races and take a pluralistic view.

Finally, the details of this studys' limitations was on the factor of intention to turnover of foreign workers which are summarized as follows.

First, in terms of methodology, the content of the questionnaire was translated into the languages of each country, and the survey was conducted through specialized survey institutions, which clearly had strengths in the sampling procedure, the visit questionnaire, and the representativeness of the sample. However, because foreign workers answered all questions in a self-report, subjectivity or cultural differences in the response still remained. As a result, there were many 'unknown' responses for all variables, and by processing those missing responses, many respondents were excluded from actual statistical analysis. By analyzing the causes of these 'unknown' responses, it is necessary to find ways to increase sincere responses.

Second, unlike surveys aimed at academic research, all psychological variables were measured as a single item because data was collected for the purpose of current status analysis and policy establishment. Considering the fact that the variables questioning the psychological aspects should be measured by multiple items (Schwab, 1990), the single item measurement method should be recognized as a clear limitation.

Third, most of the foreign workers included in this study were concentrated in Vietnam, Indonesia, and the Philippines, so the effects of various cultural differences could not be considered. Considering that the cultural difference may cause a difference in the recognition of fairness or the degree of conflict, it is not controlled even though the effect of cultural difference may be important due to the characteristics of these samples. Therefore, further analysis will be possible if foreign workers from various countries are included in the sample in the future.

Since the low-skilled foreign workforce policy so far has been in the stage of preparation and settling, if discussions were made based on the logic of control and efficiency, a more systematic and comprehensive approach to meet the changing labor market environment in the medium to long term is necessary in the future. As part of such efforts, this study comprehensively considered the various aspects of the organization such as contract satisfaction, compensation, fairness of work, and relationship conflict in order to explain the job satisfaction and turnover intention of the rapidly increasing foreign workers after the EPS. Since phenomena such as motivation and turnover in the workplace are caused by the combined effects of various factors, this diversified consideration is considered to be very important in the study of employees' attitudes. While compensation is a very important factor influencing the attitudes and performance of foreign workers, other factors, such as work fairness and interpersonal relationships, also need to be taken into account.

Although this study focuses on the turnover of foreign workers, the effective management of foreign workers will 
require long-term efforts such as education and building a cultivation culture, so a more integrated research will be needed in the future.

\section{References}

Hofstede, G. (2001). Culture's consequences: Comparing values, behaviors, institutions, and organizations across nations. CA: Sage.

Jehn, K. A. (1995). A multimethod examination of the benefits and detriments of intragroup conflict. Administrative Science Quarterly, 40(2), 256-282.

Jehn, K. A., Northcraft, G. B., \& Neale, M. A. (1999). Why differences make a difference: A field study of diversity, conflict and performance in work groups. Administrative Science Quarterly, 44(4), 741-763.

Kim, A. E. (2009). Global migration and South Korea: Foreign workers, foreign brides and the making of a multicultural society. Ethnic and Racial Studies, 32(1), 70-92.

Kim, W. B. (2004). Migration of foreign workers into South Korea: From Periphery to semi-periphery in the global labor market. Asian Survey, 44(2), 316-335.

Nass, C. \& Lee, K. M. (2001). Does computer-synthesized speech manifest personality? Experimental tests of recognition, similarity-attraction, and consistencyattraction. Journal of Experimental Psychology, 7(3), 171-181.

Pelled, L. H., Eisenhardt, K. M., \& Xin, K. R. (1999). Exploring the black box: An analysis of work group diversity, conflict and performance. Administrative Science Quarterly, 44(1), 1-28.

Phillips, J. (1998). Effects of realistic job previews on multiple organizational outcomes: A meta-analysis. Academy of Management Journal, 41(6), 673-690.

Robinson, S. L. (1996). Trust and breach of the psychological contract. Administrative Science Quarterly, 41(4), 574-599.

Robinson, S. L. \& Rousseau, D. M. (1994). Violating the psychological contract: Not the exception but the norm. Journal of Organizational Behavior, 15(3), 245-259.

Rousseau, D. M. (1989). Psychological and implied contracts in organizations. Employee Responsibilities and Rights Journal, 2(2), 121-139.

Schwab, D. (1999). Research methods for organizational studies. Mahwah, NJ: Lawrence Erlbaum Associates.

Sweeney, P. D. \& McFarlin, D. B. (1993). Workers' Evaluations of the "Ends" and the "Means": An Examination of Four Models of Distributive and Procedural Justice. Organizational Behavior and Human Decision Processes, 55(1), 23-40.

Yamanaka, K. (1993). New immigration policy and unskilled foreign workers in Japan. Pacific Affairs, 66(1), 72-90.

Prescott, P. A. (1986). Vacancy, stability and turnover of registered nurses in hospitals. Res Nurs Health, 9, 51-60.

Ward, L. S. (2007). Preliminary tests of an ecological model of Hispanic farm worker health. Public Health Nurs, 24(6), 554-564.

Wong, D. F. K., He, X., Leung, G., Lau, Y., \& Chang, Y. (2008). Mental health of migrant workers in China: Prevalence and correlates. Soc Psychiatr Psychiatr Epidemiol, 43, 483-489.

Wong, D. F. K., \& Song, H. X. (2008). The resilience of migrant workers in Shanghai China: The roles of migrant stress and meaning of migration. Int J Soc Psychiatry, 54(2), 131-143. 